\title{
Sternal cable wires for sternal closure in moderately or extremely obese patients undergoing cardiac surgery
}

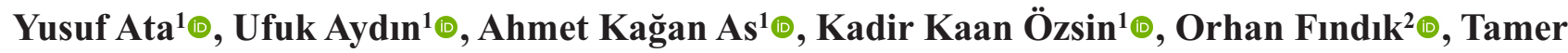 \\ Türk1®
}

${ }^{1}$ Department of Cardiovascular Surgery, University of Health Sciences, Bursa Yüksek İhtisas Training and Research Hospital, Bursa, Turkey

${ }^{2}$ Department of Cardiovascular Surgery, Derince Training and Research Hospital, Kocaeli, Turkey

DOI: $10.18621 /$ eurj.429502

\begin{abstract}
Objectives: Sternal dehiscence is a frequent complication after cardiac surgery. Our study focused on the efficiency of a sternal cable system combined with conventional steel wires for sternal fixation in patients suffering from moderate or extreme obesity and undergoing cardiac surgery.

Methods: Prospectively collected data from 22 male and 41 female patients (a mean body mass index [BMI] of $37.9 \pm 2.5 \mathrm{~kg} / \mathrm{m}^{2}$ ) who underwent major cardiac surgery via median sternotomy and sternal closure using a multifilament sternal cable system were retrospectively reviewed and analyzed.

Results: All patients were closed with a conjunction of two sternal cables and two traditional steel wires. There were two mortalities. There were no occurrences of sternal dehiscence or deep mediastinitis. Three patients suffered superficial sternal wound infections. The mean hospitalization time was $8.4 \pm 2.5$ days.

Conclusion: Our study showed that our surgical technique using a sternal cable system in combination with conventional wires decreased the incidence of sternal dehiscence in moderately and extremely obese patients.
\end{abstract}

Keywords: Sternal dehiscence, cardiac surgery, obesity

Received: June 1, 2018; Accepted: June 14, 2018; Published Online: September 24, 2018

$\mathbf{M}$ edian sternotomy is the most commonly used incision and provides excellent access to the heart and surrounding structures for the performance of cardiopulmonary bypass in cardiac surgery. However, the proper closure of the incision is difficult.

Although rare, sternal dehiscence occurs in 0.5$5 \%$ of patients, requires reoperation and carries significant mortality and morbidity risk at $10-40 \%[1,2]$. In addition to causing significant pain for the patient, sternal dehiscence also predisposes patients to developing deep sternal wound infections and mediastinitis, resulting in a high mortality rate up to $25 \%$ [3-5]. Fur- thermore, prolonged hospitalization results in higher costs. Previously, obesity has been shown to be the single most important risk factor for postoperative sternal dehiscence $[6,7]$. Therefore, effective primary closures of median sternotomies are important for preventing high-risk complications and patient discomfort especially in obese patients.

Although many different sternal closure devices have been introduced in past decades, none have been able to fully replace traditional steel wires in terms of practicability and costs. Sternal dehiscence remains an unsolved problem after cardiac surgery especially in

Address for correspondence: Tamer Türk, MD., Professor, University of Health Sciences, Bursa Yüksek Ihtisas Training and Research Hospital, Department of Cardiovascular Surgery, Mimar Sinan Mah., Emniyet Cad., No: 35, 16310 Bursa, Turkey

E-mail: tturkon@yahoo.com 
obese patients. This article reports on promising results for sternal closure in moderately (i.e., a body mass index [BMI] ranging from 35 to 39.9) and extremely obese $(\mathrm{BMI} \geq 40)$ patients with a combination of traditional steel wires and a new sternal cable system (Pioneer Surgical Technology, Inc., Marquette, Michigan, USA).

\section{METHODS}

Prospectively collected data from 63 patients (22 males and 41 females with a mean age of $64.3 \pm 7.6$ years) who underwent major cardiac surgery via median sternotomy and sternal closure using a multifilament sternal cable system between January 2014 and February 2016 were retrospectively reviewed and analyzed. Study protocol was approved by the local ethics committee. Informed consent was obtained before operation ( 24 hours) from each patient.

The BMI is calculated as weight $(\mathrm{kg}) /$ height squared $\left(\mathrm{m}^{2}\right)$. The weight classification for this study was performed using the American National Institutes of Health guidelines with normal BMIs ranging from 18.5 to 24.9, mildly obese BMIs from 25 to 34.9, moderately obese BMIs from 35 to 39.9, and extremely obese BMIs $>40$ [8]. The mean BMI of our study population was $37.9 \pm 2.5 \mathrm{~kg} / \mathrm{m} 2$ (ranging from 35 to 47.6). Fifty-four patients were classified as moderately obese, and nine patients were classified as extremely obese.

All patients received the same prophylactic antibiotic protocol, i.e., cephazolin. Perioperative risk factors were noted. The patient demographics are presented in Table 1.

\section{Surgical Technique}

The Pioneer ${ }^{\circledR}$ Sternal Cable System is an improved alternative to the traditional monofilament sternal wire. This system consists of multi-strand stainless steel $1.0-\mathrm{mm}$ diameter cables tensioned and secured using Pioneer's patented tensioner/crimper instrument. The insertion and removal of the cable is safe and easy due to its smoothness and flexibility. The tensioner assures adequate tension is applied, whereas a tension scale ensures each cable is tensioned to the same degree before crimping. Multiple figure-eight constructs work as one unit to provide optimal stabilization.

Sternal cables were deployed in a figure-eight fashion around the sternum in all patients, and conventional stainless steel wires were added around the manubrium and the lower part of the sternal body. Two multifilament cable wires were used for sternal closure, and two conventional stainless steel wires were used in the procedure. First, two simple interrupted conventional steel wires were placed separately in the proximal part of the manubrium and the distal part of the sternal body. Then, two sternal cables were deployed in a figure-eight pattern in the distal part of the manubrium and around the sternal body (Figure 1). If required, another conventional steel wire was added in the distal part of the sternal body. The conventional steel wires helped in maintaining sternal closure as the sternal cables were crimped. By

Table 1. Characteristics of patients

\begin{tabular}{lccc}
\hline Characteristics & $\mathbf{n}$ & $\mathbf{\%}$ & Mean \pm SD (range) \\
\hline Age (years) & & & $64.3 \pm 7.6(46-83)$ \\
BMI (kg/m ${ }^{2}$ ) & 9 & 14.3 & $37.9 \pm 2.5(35-47.6)$ \\
BMI $>$ 40 & 42 & 66.7 & \\
Sex (female) & 24 & 38.1 & \\
DM & 19 & 30.2 & \\
COPD & 4 & 6.3 & \\
Renal insufficiency & 27 & 44.3 & $64.3 \pm 15.3(32-109)$ \\
Smoking & & $91.4 \pm 19.4(54-149)$ \\
X clamp (min) & & \\
Perfusion (min) & & \\
\hline BMI = body mass index, COPD = chronic obstructive pulmonary disease, DM $=$ diabetes mellitus, X \\
clamp = aortic cross clamp
\end{tabular}




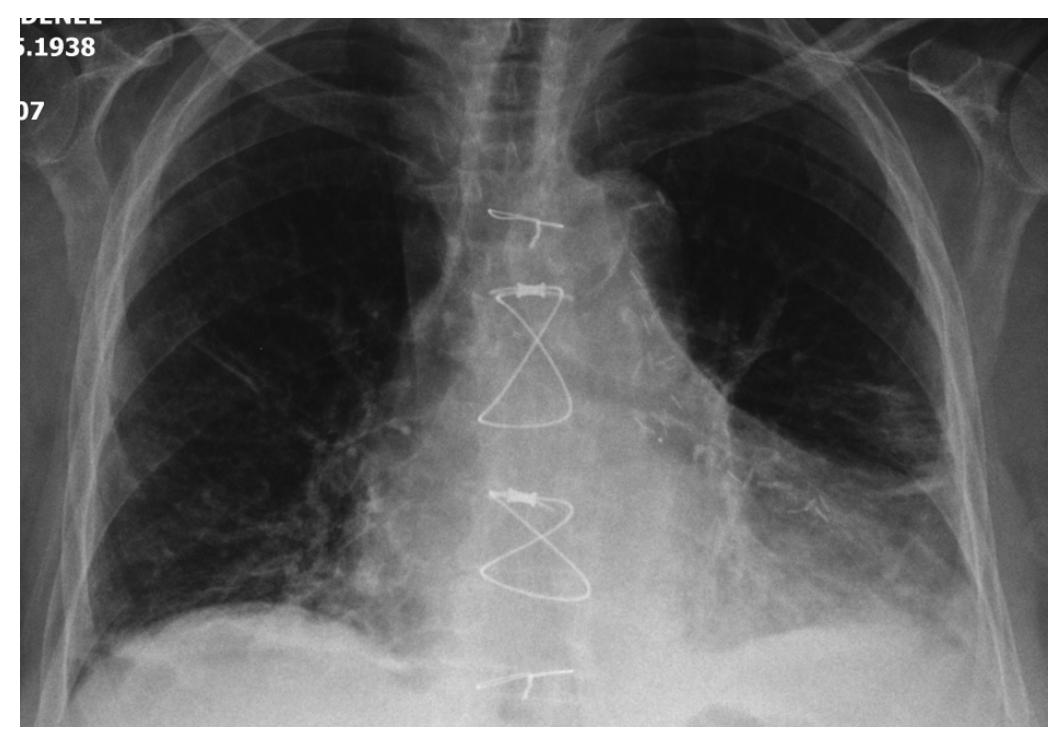

Figure 1. X-Ray of a patient closed with sternal cable system.

using this technique, the crimping of the cables was proper and easily executed. Only five patients required additional conventional steel wires for approximation due to the length of the sternal body.

\section{RESULTS}

All patients were closed with a conjunction of two Pioneer Cable System wires and two conventional steel wires. A majority of the patients underwent isolated CABG (54/63) with the use of left internal thoracic artery (LITA). Nine patients underwent open cardiac surgery other than CABG. The surgical interventions of the patients are shown in Table 2.

In five patients, a third conventional steel wire was added in the distal part of the sternal body due to

Table 2. Surgical procedures

\begin{tabular}{lcc}
\hline Variables & $\mathbf{n}$ & $\mathbf{\%}$ \\
\hline CABG & 54 & 85.7 \\
AAR & 3 & 4.8 \\
CABG+MVR & 2 & 3.2 \\
DVR & 2 & 3.2 \\
MVR & 1 & 1.6 \\
AVR & 1 & 1.6 \\
\hline
\end{tabular}

$\mathrm{AAR}=$ ascendant aorta replacement, $\mathrm{AVR}=$ aortic valve replacement, $\mathrm{CABG}=$ coronary artery bypass grafting, $\mathrm{DVR}$ $=$ double valve replacement, $\mathrm{MVR}=$ mitral valve replacement length of the sternum. There were $2(3.2 \%)$ mortalities. Both patients died due to low cardiac output and multiple organ failure, one on the $12^{\text {th }}$ and the other on the $19^{\text {th }}$ postoperative day. There were no sternal dehiscence or deep mediastinitis in the whole group. Three $(4.8 \%)$ patients suffered superficial sternal wound infections. The mean postoperative drainage was $490 \pm 142.6 \mathrm{ml}$, and the mean hospitalization time was $8.4 \pm 2.5$ days. The operative and postoperative variables are presented in Table 3 .

Table 3. Postoperative variables

\begin{tabular}{lccc}
\hline Variables & $\mathbf{n}$ & $\mathbf{\%}$ & Mean \pm SD (range) \\
\hline $\begin{array}{l}\text { Drainage, ml } \\
\text { Hospitalization, days }\end{array}$ & & & $490 \pm 142.6(150-750)$ \\
$\begin{array}{l}\text { Sternal dehiscence } \\
\begin{array}{l}\text { Superficial wound } \\
\text { infection }\end{array}\end{array}$ & 0 & 0 & $8.4 \pm 2.5(6-19)$ \\
\hline
\end{tabular}

\section{DISCUSSION}

Sternal dehiscence is a serious complication after cardiac surgery. The instability of the chest wall and the higher risk for infection leads to high mortality and morbidity rates. Our study focused on the efficiency and mechanical fatigue performance of a sternal cable system combined with conventional steel wires for sternal fixation in patients suffering from moderate or 
extreme obesity, i.e., major risk factors for sternal dehiscence after cardiac surgery.

The loosening and failure of a sternal closure is associated with compromised wound healing and may lead to sternal wound dehiscence and infection [9]. Complications due to median sternotomy have been reported to occur in $0.3 \%$ to $5.0 \%$ of patients and are associated with significant morbidity and mortality rates of $14 \%$ to $47 \%$ with a high risk of mortality especially in cases of mediastinitis $[3,10]$.

Sternal dehiscence has been shown to be of major concern by Molina et al. [6]. When the BMI is greater than 30 , sternal dehiscence occurs at an incidence of $6.46 \%$, whereas the occurrence of sternal dehiscence is $1.63 \%$ in non-obese patients. Kiessling et al. [11] reported that when sternal closures were performed with conventional steel wires, there was a $12 \%$ incidence of sternal dehiscence in obese patients with a mean BMI of $34.6 \pm 1.7 \mathrm{~kg} / \mathrm{m} 2$, whereas the incidence of dehiscence of the whole study group of 100 patients was $7 \%$. In our study group consisting of 61 patients with a mean BMI of $37.9 \pm 2.5 \mathrm{~kg} / \mathrm{m}^{2}$ there were no sternal dehiscences.

A variety of sternum closure techniques have been developed. The primary aim in selecting the appropriate closure technique should be in its effectiveness to ensure a rigid closure of the sternum to restore stability to the sternum. A variety of sternal closure techniques using different closure materials have been reported to prevent sternal dehiscence. However, no ideal, standardized method has been adopted. In a meta-analysis by Khasati et al. [12] comparing simple wire and figure-eight closure techniques found that the figure-eight method had no significant benefit over the simple wire method. Grapow et al. [13] used a new material named ZipFix, which showed promising results. Wangsgard et al. [14] reported that the figure-eight stainless steel cable system and the dynamic sternal fixation plate system were expected to show lower failure rates when compared with the figure-eight stainless-steel wire system. Our findings with no sternal dehiscence and only three superficial wound infections supported the experimental findings of Wangsgard et al. [14].

The sternal cables of the Pioneer sternal cable system have been reported to have fatigue strengths approximately ten times stronger than standard steel wires [15]. The sternal cables are wrapped around the sternum in a figure-eight pattern, uniformly hugging the sternal bone to minimize micro-motion and wire loosening, which would otherwise result in lower postoperative non-union potential and compromised wound healing.

Oh et al. [10] used sternal cables in 781 patients and conventional steel wires in 573 patients and did not find any clear clinical advantages of sternal cables over conventional steel wires. However, the mean BMI values of the cable group and the conventional wire group were $24.1 \pm 3.2 \mathrm{~kg} / \mathrm{m}^{2}$ and $23.9 \pm 3.1$ $\mathrm{kg} / \mathrm{m}^{2}$, respectively, i.e., the moderately or severely obese patient population was very low in the whole study group especially compared with the mean 37.9 $\pm 2.5 \mathrm{~kg} / \mathrm{m}^{2}$ BMI of our study group.

In a recent study by Ozen et al. [16], the authors compared 24 obese patients (mean BMI $34.4 \pm 3.1$ $\mathrm{kg} / \mathrm{m}^{2}$ ) on whom they used the sternal cable system with 32 obese patients (mean BMI $34.2 \pm 2.7 \mathrm{~kg} / \mathrm{m}^{2}$ ) on whom they used conventional wires for sternal closures. Ozen et al. [16] did not observe any sternal dehiscence in the cable group and observed 3 incidences $(9.4 \%)$ of sternal dehiscence in the conventional wire group (a non-significant difference). However, the study group was too small to reach a definitive conclusion. The main difference between the cable groups in the Ozen et al. [16] study and in our study was that our group consisted of moderately or severely obese patients. Furthermore, our surgical technique was of lower cost due to the utilization of two sternal cables on each patient compared with the use of three sternal cables in the Ozen et al. [16] study. The sternal cable group of 24 patients in the study by Ozen et al. revealed a satisfactory result with no postoperative sternal dehiscence. Similarly, none of the 63 patients in our study suffered postoperative sternal dehiscence when compared with the obese patient groups in the studies conducted by Molina et al. [6] and Kiessling et al. [11] (with 6.46\% and 12\% incidence rates of sternal dehiscence, respectively). The patients in the latter two studies utilized conventional steel wires in a traditional way for sternal closure. Additionally, our study group consisted of more obese patients with a mean BMI of $37.9 \pm 2.5$ $\mathrm{kg} / \mathrm{m}^{2}$.

Oh et al. [10] and Ozen et al. [16] also reported decreased postoperative bleeding. Total postoperative drainage was $499.0 \pm 218.3 \mathrm{ml}$ in the cable group and 
$741.9 \pm 243.3 \mathrm{ml}(p<0.001)$ in the steel wire group in the study of Ozen et al. In the study by Oh et al. [10], 17 patients in the cable group and 29 patients in the conventional wire group underwent reoperation for bleeding ( $p=0.068)$. Although this comparison was not significant, the results indicate a tendency for decreased sternal bleeding. This tendency may be attributed to the ability for the sternal cable wires to hold the sternum at a higher tension around the bone more than conventional steel wires. This would allow for a tighter and more stable fixation of the sternum and lead to decreased bleeding from bone marrow and nearby structures. In our study, one reoperation was required for bleeding, and the mean drainage was 490 $\pm 142.6 \mathrm{ml}$.

Generally, sternal dehiscence occurs when sternal steel wires cut through the bone or in rare cases, when the suture material breaks. As conventional sternal closure techniques and conventional wires find continued use in obese patients, the incidence of sternal dehiscence will continue to occur at high rates. If the rate of obesity continues to increase, higher incidences of sternal dehiscence will result in increased mortality and morbidity rates and higher hospital costs.

The sternal cables are easy to handle and may decrease the time required for sternum closure. The cables are more flexible than the traditional steel wires. This enables a surgeon to more easily complete a figure-eight suture and allows the cable to more uniformly hug the sternum to decrease the chance for the cable to cut into the sternal bone. Additionally, the flexibility of the cable wires allows for active motion of the chest and the sternal bone. Additionally, the multifilament cables are stronger than traditional wires; this minimizes wire breakage concerns for larger patients. These advantages allow for a more rigid closure and apposition of the sternal bone and likely results in increased resistance to infection. However, despite these advantages, surgeons should avoid over-tensioning sternal cables due to the likelihood of breaking or cutting through unprotected or non-immobilized soft bone tissue.

\section{Limitations}

This study has several limitations. Our study group was small and encompassed 63 moderately or extremely obese patients. While limited in number, our study population seemed to have more obese patients treated with sternal cable wires compared with other reports in the literature. Another limitation was the retrospective design of our study. Other than these limitations, our study is the first study in English literature that concerns multifilament cable wire sternal closures for a group consisting of only moderately or extremely obese patients.

\section{CONCLUSION}

Our study showed that our surgical technique using a sternal cable system in combination with conventional wires decreased the incidence of sternal dehiscence in moderately and extremely obese patients when compared with other similarly reported studies in the literature.

\section{Author's Contributions}

YA: data interpretation, manuscript revision; UA: data collection, analysis, manuscript revision; AKA: data collection, manuscript revision; KKÖ: data interpretation, manuscript revision; OF: data interpretation, manuscript revision; TT: study conception, correspondence, data collection, analysis.

\section{Conflict of interest}

The authors disclosed no conflict of interest during the preparation or publication of this manuscript.

\section{Financing}

The authors disclosed that they did not receive any grant during conduction or writing of this study.

\section{REFERENCES}

[1] Voss B, Bauernschmitt R, Will A, Krane M, Kröss R, Brockmann G, et al. Sternal reconstruction with titanium plates in complicated sternal dehiscence. Eur J Cardiothorac Surg 2008;34:139-45.

[2] John LCH. Modified closure technique for reducing sternal dehiscence; a clinical and in vitro assessment. Eur J Cardiothorac Surg 2008;33:769-73.

[3] El Oakley RM, Wright JE. Postoperative mediastinitis: classification and management. Ann Thorac Surg 1996;61:10306.

[4] Baskett RJ, MacDougall CE, Ross DB. Is mediastinitis apreventablecomplication? A 10-year review. Ann Thorac Surg 
1999;67:462-5.

[5] Bryan AJ, Lamarra M, Angelini GD, West RR, Breckenridge IM. Mediansternotomy wound dehiscence: a retrospective case control study of risk factors and outcome. J R Coll Surg Edinb 1992;37:305-8.

[6] Molina JE, Lew RSL, Hyland KJ. Postoperative sternal dehiscence in obese patients: incidence and prevention. Ann Thorac Surg 2004;78:912-7.

[7] Prabhakar G, Haan CK, Peterson ED, Coombs LP, Cruzzavala JL, Murray GF. The risks of moderate and extreme obesity for coronary artery bypass grafting outcomes: a study from the Society of Thoracic Surgeons' database. Ann Thorac Surg 2002;74:1125-31.

[8] National Institutes of Health. Clinical guidelines on the identification, evaluation, and treatment of overweight and obesity in adults. National Heart, Lung and Blood Institute. June 1998.

[9] Schimmer C, Reents W, Berneder S, Eigel P, Sezer O, Scheld $\mathrm{H}$, et al. Prevention of sternal dehiscence and infection in highrisk patients: a prospective randomized multicenter trial. Ann Thorac Surg 2008;86:1897-904.

[10] Oh YN, Ha KJ, Kim JB, Jung SH, Choo SJ, Chung CH, et al. Multifilament cable wire versus conventional wire for sternal closure in patients undergoing major cardiac surgery. Korean J
Thorac Cardiovasc Surg 2015;48:265-71.

[11] Kiessling AH, Isgro F, Weisse U, Möltner A, Saggau W, Boldt J. Advanced sternal closure to prevent dehiscence in obese patients. Ann Thorac Surg 2005;80:1537-9.

[12] Khasati N, Sivaprakasam R, Dunning J. Is the figure-of-eight superior to the simple wire technique for closure of the sternum? Interact Cardiovasc Thorac Surg 2004;3:191-4.

[13] Grapow MT, Melly LF, Eckstein FS, Reuthebuch OT. A new cable-tie based sternal closure system: description of the device, technique of implantation and first clinical evaluation. J Cardiothorac Surg 2012;7:59.

[14] Wangsgard C, Cohen DJ, Griffin LV. Fatigue testing of three peristernal median sternotomy closure techniques. J Cardiothorac Surg 2008;3:52.

[15] Pioneer Surgical Technology Inc. Pioneer sternal cable system: cardiothoracic: cable system [Internet]. Marquette (MI): Pioneer Surgical Technology Inc.; c2015 [cited 2014 Dec 27]. Available from: http://www.pioneersurgical.com/cardiothoracic/CableSystem/Pioneer-Sternal-Cable-System/ [16] Özen Y, Sarıkaya S, Rabuş MB, Günay D, Aksoy E, Dedemoğlu $\mathrm{M}$, et al. Comparison of the sternal wires and sternal cable in closure of the sternum during cardiac surgery. Cardiovasc Surg Interven 2014;1:41-4. 